\title{
THE INFLUENCE OF CASTING VELOCITY ON STRUCTURE OF AI CONTINUOUS INGOTS
}

\begin{abstract}
The aim of paper was determination of influence of the casting velocity in horizontal continuous casting process on solidification phenomenon and next primary structure of aluminum ingots. In the range of studies was conducted the experiment concerning continuous casting of $\mathrm{Al}$ ingots with diameter $30 \mathrm{~mm}$ at velocity from 30 to $80 \mathrm{~mm} / \mathrm{min}$. Moreover was developed adequate to the real the virtual model of cooled water continuous casting mould, which was used in simulation of solidification process of Al continuous ingot, made in ANSYS Fluent software. In result was determined the influence of casting velocity and temperature of cooling water on position of crystallization front inside the continuous casting mould. While the shape and size of grains in primary structure of Al continuous ingots were determined on the basis of metallographic macroscopic studies. On the basis of the results analysis was affirmed that increase of casting velocity strongly influences on position of crystallization front and causes increase of temperature of ingot leaving the continuous casting mould. In result the increase of casting velocity supposedly leads to decrease of temperature gradient on crystallization front what creates coarse grains in primary structure of aluminum continuous ingots and caused low usable properties i.e. suitability to plastic deformation.
\end{abstract}

Keywords: aluminum, primary structure, ingot, continuous casting, simulation of solidification process

\section{Introduction}

The technology of continuous casting is applying usually in production of ingots of $\mathrm{Fe}[1-4], \mathrm{Al}[5-8]$ or $\mathrm{Cu}[9,10]$ alloys, with high yield and quality. The quality of continuous ingot in comparison with traditional gravity casting with use of ingot permanent mould concerns refinement and uniform of ingot structure, which results from solidification of metal in water cooled continuous casting mould. The important parameter of continuous casting technology which strongly influences on stability and yield of process is algorithm of ingot movement represented mainly by the casting velocity. Of course the yield of this process increases with increase in the casting velocity. However large increase in the casting velocity caused brake of process stability by move the crystallization front outside the water cooled continuous casting mould. This phenomenon decides of danger pouring out of liquid metal. While large decrease in casting velocity caused solidification on liquid metal in the channel before the continuous casting mould what decides of mechanical braking of ingot. Additionally the algorithm of ingot movement besides casting velocity depends on combination of motion to forwards, stop and backwards.

Therefore the aim of studies was determined the influence of the casting velocity in horizontal continuous casting process on solidification phenomenon and next primary structure of aluminum with a purity $99,5 \%$ ingots.

\section{Range of studies}

On Fig. 1 is presented view of the stand of horizontal continuous casting, which was constructed in Department of Foundry Engineering of Silesian University of Technology. The main parts of the made stand belong to induction furnace, which is also tundish with a capacity of up to $60 \mathrm{~kg}$ of charge, water cooled continuous casting mould at flow rate from 0.1 to $101 / \mathrm{min}$, system of recooling, system of continuous ingot drawing and cutting, which realized method of ingot movement defined by combination of motion to forwards, stop and/or backwards performed in specified time and velocity from 100 to $500 \mathrm{~mm} /$ min set in control system. The characterization of this stand to horizontal continuous casting of $\mathrm{Al}$ and its alloys is presented in detail in papers $[8,11]$.

In presented studies was applied method of $\phi 30 \mathrm{~mm}$ A199,5\% ingot movement defined by combination of motion to forwards in time of $1 \mathrm{~s}$ at velocity from 100 to $240 \mathrm{~mm} / \mathrm{min}$ and stop in time of $2 \mathrm{~s}$. In result of presented method of ingot movement in combination forwards/stop/forwards/stop/etc. was

\footnotetext{
* SILESIAN UNIVERSITY OF TECHNOLOGY, DEPARTMENT OF FOUNDRY ENGINEERING,7 TOWAROWA STR., 44-100 GLIWICE, POLAND

** SILESIAN UNIVERSITY OF TECHNOLOGY, INSTITUTE OF THERMAL TECHNOLOGY, 22 KONARSKIEGO STR., 44-100 GLIWICE, POLAND

*** SILESIAN UNIVERSITY OF TECHNOLOGY, INSTITUTE OF FUNDAMENTALS OF MACHINERY DESIGN,18A KONARSKIEGO STR., 44-100 GLIWICE, POLAND 


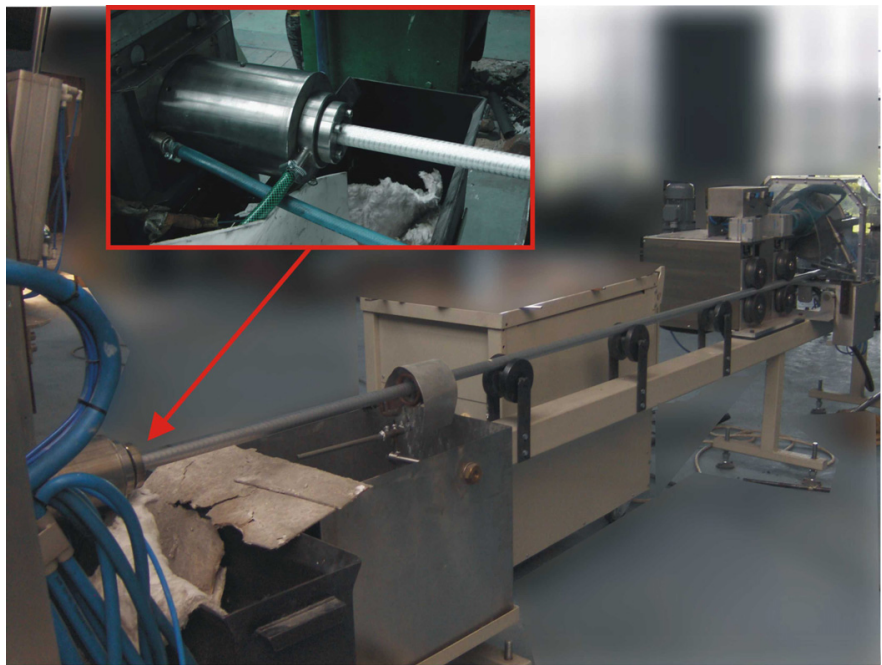

Fig. 1. View of stand of horizontal continuous casting

obtained the average casting velocity from 30 to $80 \mathrm{~mm} / \mathrm{min}$. In dependence of used velocities the temperature of cooling water in continuous casting mould was $50-90^{\circ} \mathrm{C}$ at set flow rate $0,5 \mathrm{l} /$ min, as show Fig. 2.

The temperature of ingot after leaving the continuous casting mould was estimated with use of thermal imaging camera JANOPTIC OPTICAL SYSTMS Inc. VarioCAM hr head 600. The increase in the average casting velocity of each $10 \mathrm{~mm} / \mathrm{min}$, results in the temperature of ingot increase of $20^{\circ} \mathrm{C}$. Therefore in dependence of used velocities the temperature of ingot after leaving the continuous casting mould was $120-220^{\circ} \mathrm{C}$, as show Fig. 3 .

On Fig. 4 is presented view of the water cooled continuous casting mould. This continuous casting mould contains two main parts i.e. $250 \mathrm{~mm}$ length stainless steel cooling worm with cross-sectional area of the cooling channel $200 \mathrm{~mm}^{2}$ and graphite tube with wall thickness $5 \mathrm{~mm}$ inside which is followed solidification of liquid metal. On this bases was developed adequate to the real the virtual model of cooled water continuous casting mould, which was used in simulation of solidification process of Al continuous ingot, made in ANSYS Fluent software (Fig. 5).

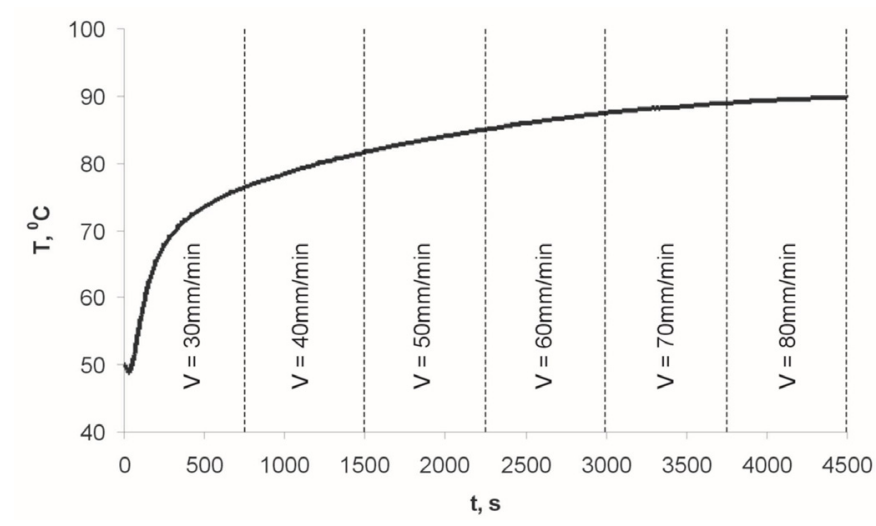

Fig. 2. The temperature of cooling water in the continuous casting mould $(\mathrm{T})$ in dependence of the average velocity $(\mathrm{V})$ in time $(\mathrm{t})$ of continuous

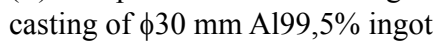

While the influence of the average casting velocity on primary structure of pure Al ingots was estimated on the basis of results of macroscopic metallographic studies. Analyzed surface of cross-section of ingots for macroscopic analysis was etched with use of solution of: $50 \mathrm{~g} \mathrm{Cu}, 400 \mathrm{ml} \mathrm{HCl}, 300 \mathrm{ml} \mathrm{HNO}_{3}$ and $300 \mathrm{ml} \mathrm{H}_{2} \mathrm{O}$. a)

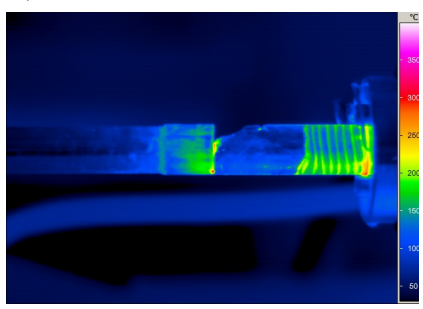

e)

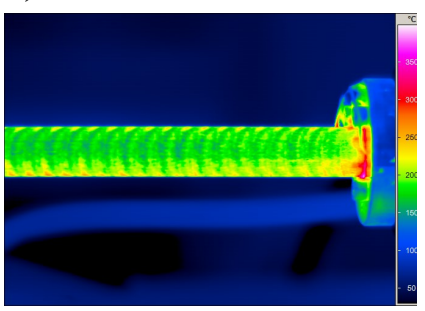

b)

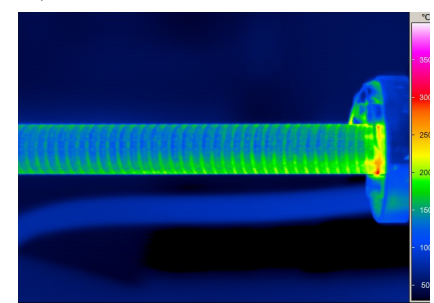

f)

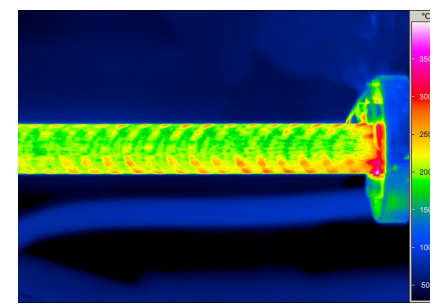

c)

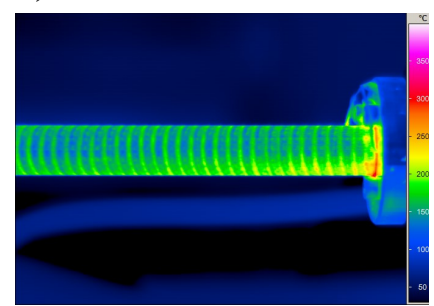

g)

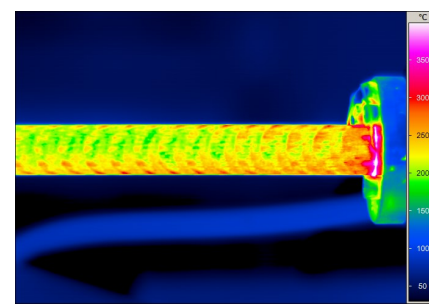

d)

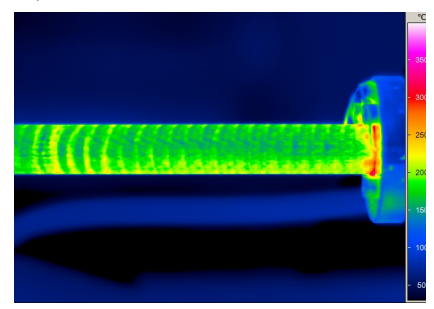

Fig. 3. Thermal image of $\mathrm{Al}$ ingot after leaving the continuous casting mould at the average casting velocity: a) $30 \mathrm{~mm} / \mathrm{min}$ with visible dummy bar (on left side), b) $30 \mathrm{~mm} / \mathrm{min}$, c) $40 \mathrm{~mm} / \mathrm{min}$, d) $50 \mathrm{~mm} / \mathrm{min}$, e) $60 \mathrm{~mm} / \mathrm{min}$, f) $70 \mathrm{~mm} / \mathrm{min} \mathrm{and} \mathrm{g)} 80 \mathrm{~mm} / \mathrm{min}$

\section{Results of studies}

On Fig. 6 are presented macrostructures of Al with a purity of $99,5 \%$ continuous ingots in dependence of the average cast- ing velocities. On the basis of obtained results was affirmed that is present negative influence on primary structure of increase of average velocity of ingot movement. It was found that at small average casting velocity the primary structure of $\mathrm{Al}$ ingot 


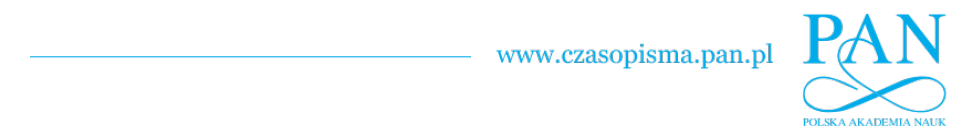

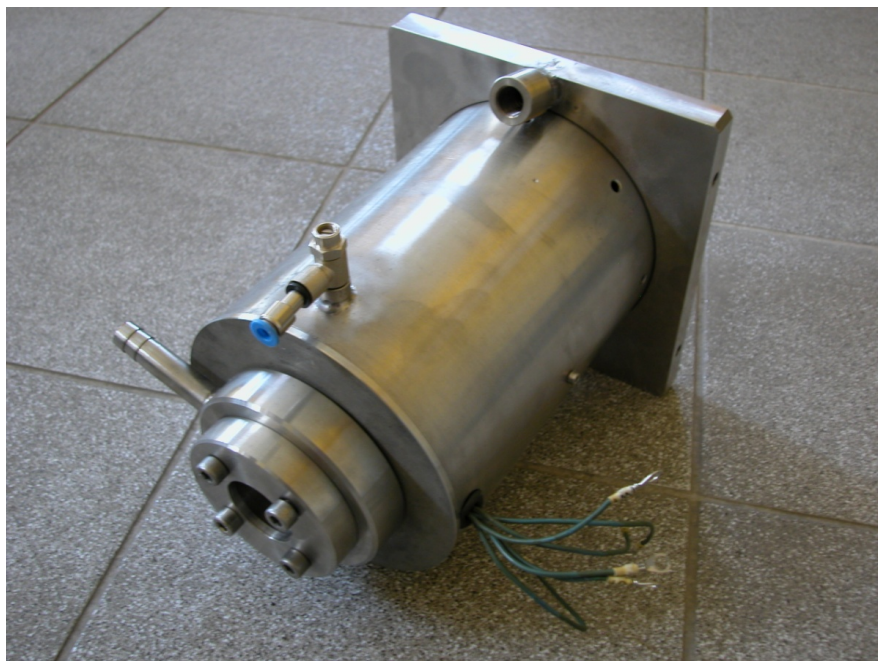

Fig. 4. View of the water cooled continuous casting mould

a)

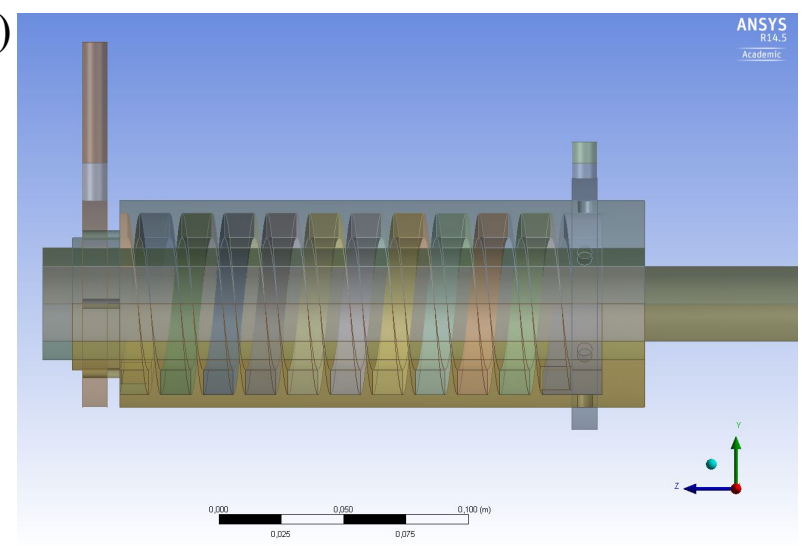

contains mainly favorable equiaxed grains and small amount of unfavorable columnar grains. Whereas cast with high velocities decides of increases in amount of columnar grains at the expense of equiaxed grains.

Whereas on Figs. 7,8 are presented results of computer simulation of solidification process of Al continuous ingot. In details on Fig. 7 is presented position of the crystallization front inside the continuous casting mould in dependence of the average casting velocity. Whereas on Fig. 8 is presented distribution of ingot temperature in dependence of the average casting velocity too.

Summarize on the basis of the analysis of conducted studies was found that increase of average casting velocity supposedly leads to decrease of temperature gradient on crystallization front what creates coarse grains in primary structure of aluminum continuous ingots and caused low usable properties i.e. suitability

b)

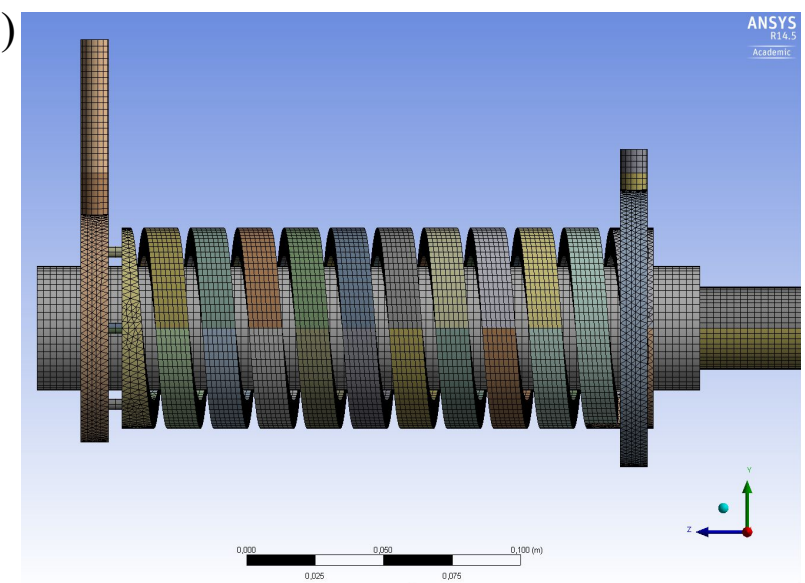

Fig. 5. The 3D simulation model of water cooled continuous casting mould:a) geometry, b) division of the finite element (meshing)

a)

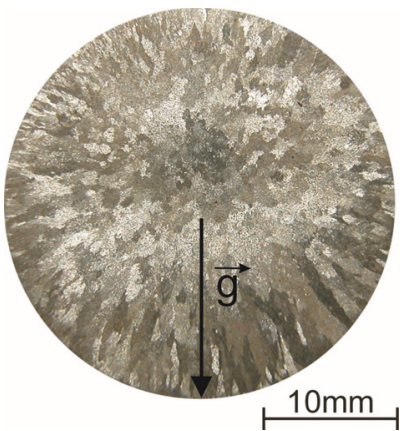

d)

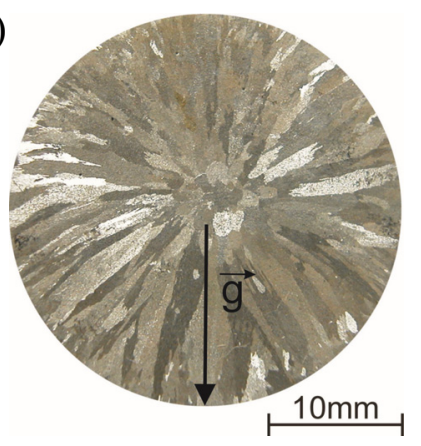

b)

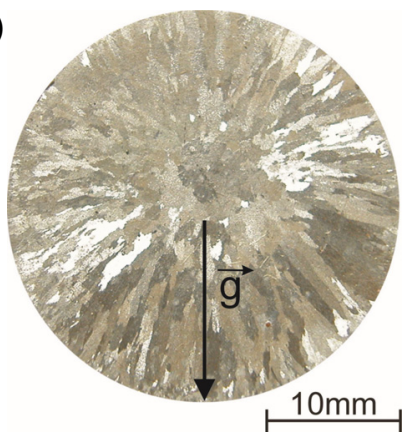

e)

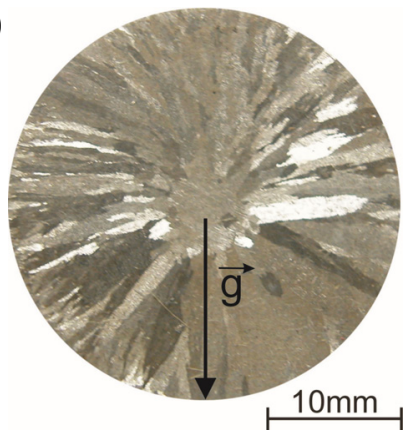

c)

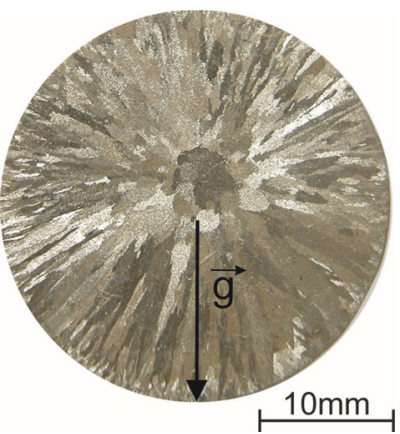

f)

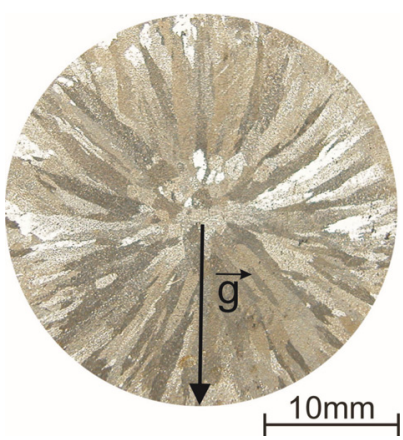

Fig. 6. Cross-section macrostructures of A199,5\% continuous ingots in dependence of the average of casting velocities: a) $30 \mathrm{~mm} / \mathrm{min}$, b) $40 \mathrm{~mm} /$ min, c) $50 \mathrm{~mm} / \mathrm{min}$, d) $60 \mathrm{~mm} / \mathrm{min}$, e) $70 \mathrm{~mm} / \mathrm{min}$ and f) $80 \mathrm{~mm} / \mathrm{min}$; g - gravitational acceleration 
a)

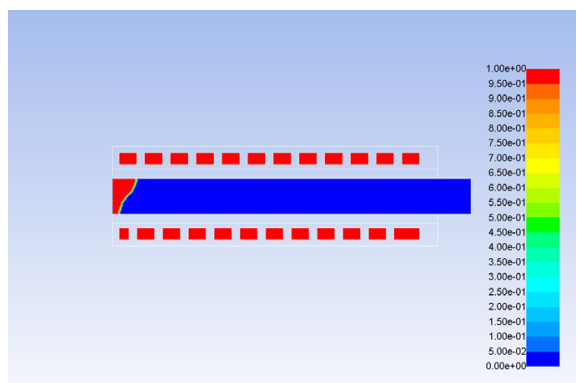

Contours of Liquid Fraction (Time=1.1350e+03)

d)

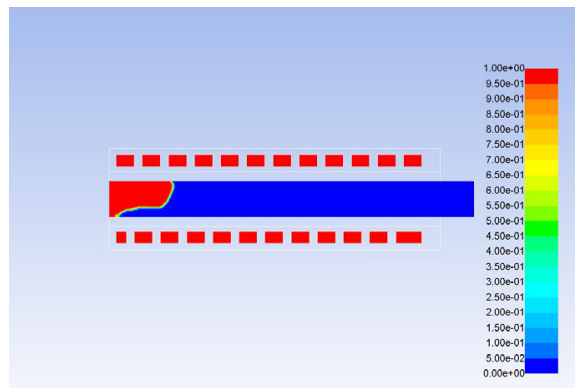

b)

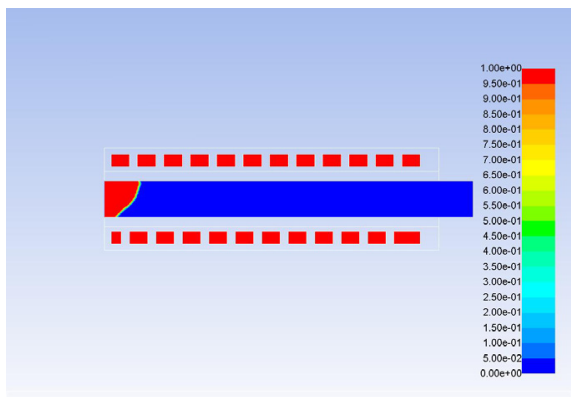

e)

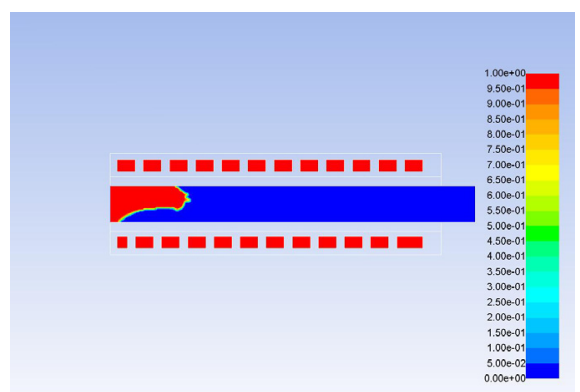

c)

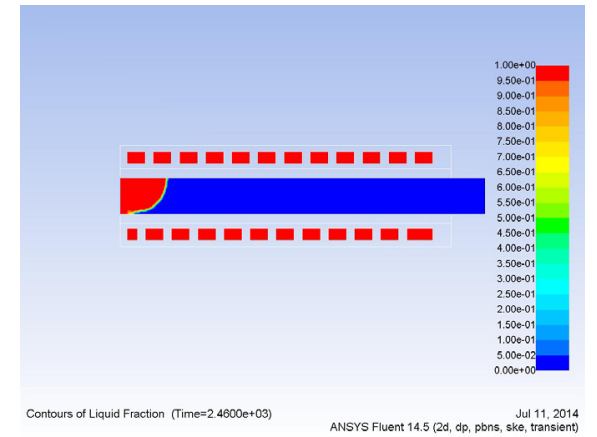

f)

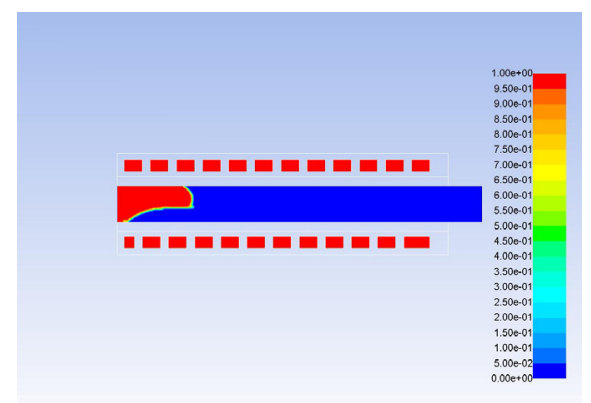

Fig. 7. The influence of the average casting velocity on position of crystallization front (the scale shows the percentage of liquid phase) in horizontal continuous casting process of A199,5\%: a) $30 \mathrm{~mm} / \mathrm{min}$, b) $40 \mathrm{~mm} / \mathrm{min}$, c) $50 \mathrm{~mm} / \mathrm{min}$, d) $60 \mathrm{~mm} / \mathrm{min}$, e) $70 \mathrm{~mm} / \mathrm{min}$ and f) $80 \mathrm{~mm} / \mathrm{min}$

a)

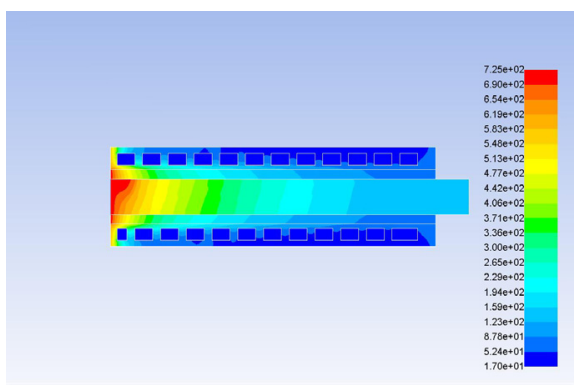

d)

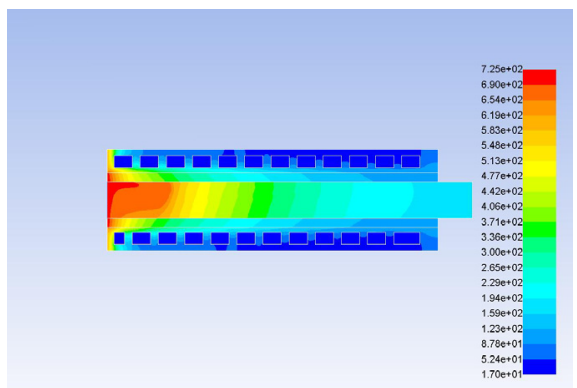

b)

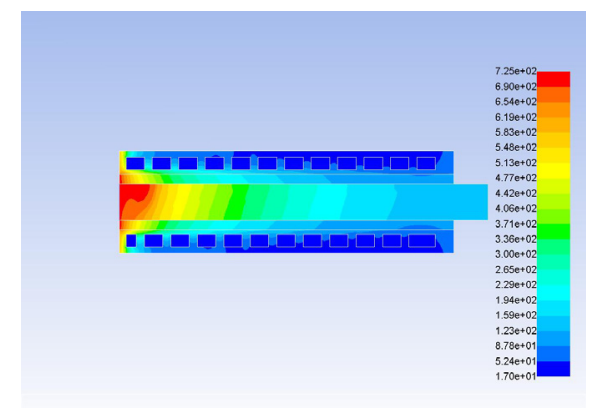

e)

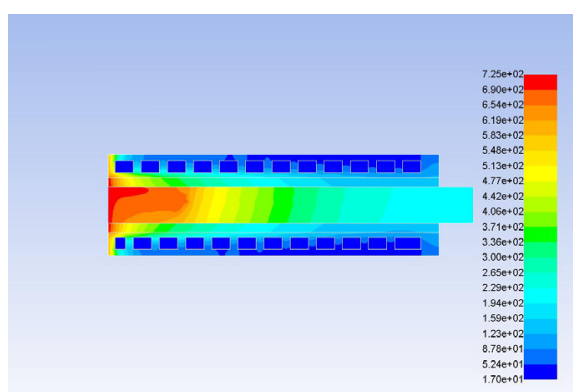

c)

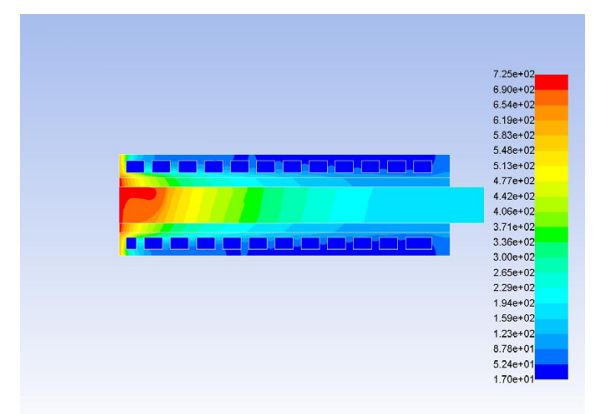

f)

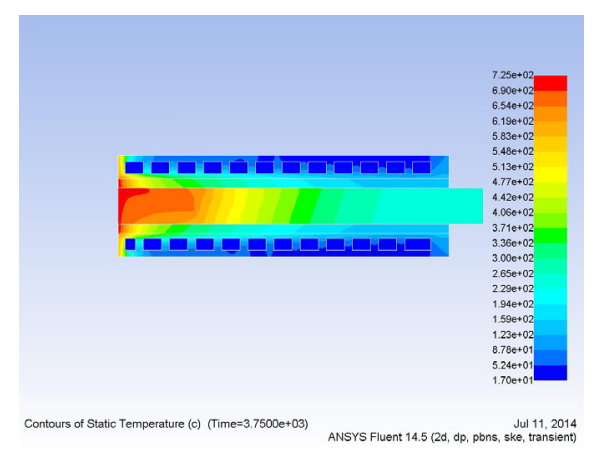

Fig. 8. The influence of the average casting velocity on ingot temperature (the scale shows the temperature values) in horizontal continuous casting process of A199,5\%: a) $30 \mathrm{~mm} / \mathrm{min}$, b) $40 \mathrm{~mm} / \mathrm{min}$, c) $50 \mathrm{~mm} / \mathrm{min}$, d) $60 \mathrm{~mm} / \mathrm{min}$, e) $70 \mathrm{~mm} / \mathrm{min}$ and f) $80 \mathrm{~mm} / \mathrm{min}$ 
to plastic deformation. The phenomenon of decrease of temperature gradient on crystallization front which strongly influences on primary structure was confirmed by results of simulation of solidification process of $\mathrm{Al}$ continuous ingot.

\section{Conclusions}

Based on the conducted studies the following conclusions have been formulated:

1. Increasing the average velocity in horizontal continuous casting of pure $\mathrm{Al}$ causes an increase in the amount of unfavorable columnar grains in primary structure of ingot, supposedly which is due to a reduced temperature gradient at the crystallization front.

2. In aim to provide a preferred primary structure of pure Al ingots are recommended applied low average velocity in horizontal continuous casting process. However, in order to increase the efficiency of this casting process it is possible to increase the average velocity but this requires the inoculation of solidifying metal by use of electromagnetic stirrer in the area of the water cooled continuous casting mould, as were shown in other papers of the authors [12,13].

3. Developed model of the continuous casting mould allows for effective study of the phenomenon of continuous ingot crystallization, i.e. to forecast the shape and position of the crystallization front and the temperature distribution in the ingot at a high similarity to the real conditions. Confirmation of this finding is the shape of the crystallization front shown in Fig. 7, which corresponds to the shape of the broken ingot presented on Fig. 9 and visibly on Fig. 10 displacement of principal axis of the ingot.

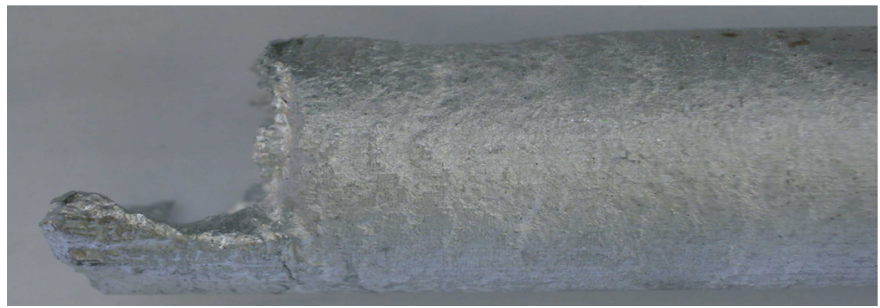

Fig. 9. View of the broken aluminum ingot in studied horizontal continues casting process

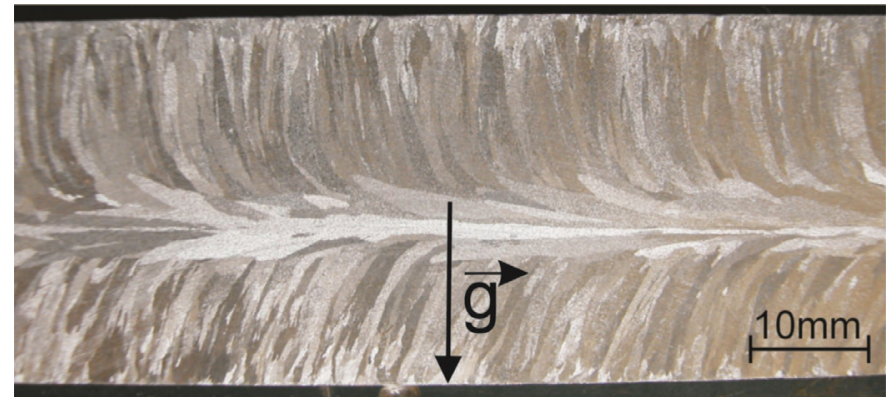

Fig. 10. Longitudinal macrostructure of A199,5\% continuous ingots at the average casting velocity $50 \mathrm{~mm} / \mathrm{min}$ (direction of casting to the right); $\mathrm{g}$ - gravitational acceleration

\section{REFERENCES}

[1] K. Miyazawa, Science and Technology of Advanced Materials 2 (1), 59-65 (2001)

[2] S. Zhou, H. Li, J. Rao, Z. Ren, J. Hang, Z. Yang Z, China Foundry 4 (3), 198-201 (2007).

[3] J. Szajnar, M. Stawarz, T. Wróbel, W. Sebzda, B. Grzesik, M. Stępień, Archives of Materials Science and Engineering 42 (1), 45-52 (2010).

[4] J. Szajnar, M. Stawarz, T. Wróbel, W. Sebzda, Archives of Foundry Engineering 10 (3), 171-174 (2010).

[5] D. Lee, S. Kang, D. Cho, K. Kim, Rare Metals 25, 118-123 (2006).

[6] Z. Beijiang, C. Jianzhong, L. Guimin, Materials Science \& Engineering A A355, 325-330 (2003).

[7] Y. Li, X. Zhang, F. Jia, S. Yao, J. Jin, Transactions of Nonferrous Metals Society of China 13 (2), 365-368 (2003).

[8] T. Wróbel, J. Szajnar, in: Proceedings of $22^{\text {nd }}$ International Conference on Metallurgy and Materials METAL 2013, May 15-17.2013, Brno, Czech Republic, 1177-1182.

[9] Z. Yan, W. Jin, T. Li, Journal of Materials Engineering and Performance 21 (9), 1970-1977 (2012).

[10] X. Li, Z. Guo, X. Zhao, B. Wei, F. Chen, T. Li, Materials Science \& Engineering A 460-461, 648-651 (2007).

[11] T. Wróbel, J. Szajnar, D. Bartocha, M. Stawarz, Archives of Foundry Engineering 13 (3), 113-118 (2013).

[12] J. Szajnar, T. Wróbel, International Journal of Materials and Product Technology 33 (3), 322-334 (2008).

[13] T. Wróbel, Proceedings of $21^{\text {st }}$ International Conference on Metallurgy and Materials METAL 2012, May 23-25.2012, Brno, Czech Republic, 1114-1120. 